\title{
An ontology-based knowledge management system to support technology intelligence
}

\author{
Husam Arman, Allan Hodgson, Nabil Gindy \\ University of Nottingham, School of M3, Nottingham, UK
}

\begin{abstract}
High technology enterprises must now continually reduce costs and develop better products and services in order to sustain a competitive advantage in an endlessly changing business environment. High research and development (R\&D) costs force high technology enterprises to select more carefully which technologies to invest in.
\end{abstract}

Advanced technology planning tools enable enterprises to make better strategic decisions. Knowledge of the technological changes relevant to an enterprise represents a critical issue in enhancing the performance of that enterprise and sustaining its competitive edge.

The creation of an ontology is usually the first step towards a knowledge management system. In this paper, we describe the framework of an ontology-based knowledge management system including design and application at a real case. The proposed system was developed in the Protégé environment, a generic system that is applicable to a variety of domain applications.

Keywords: knowledge management, technology intelligence, ontology, advanced manufacturing technologies

\section{INTRODUCTION}

Technology is an important strategic asset for many companies, and technological considerations must be included in strategic planning processes [1]. Strategic technology planning can enable companies to anticipate potential technology-based threats and opportunities and so react in time to benefit from such developments. Traditional technology monitoring processes in most organizations are largely arbitrary, and are dependent on what individuals or leaders in the organization are reading, thinking and sharing informally with each other. In today's world, such an arbitrary process is insufficient.

To provide effective support for the strategic technology planning process, knowledge management involvement is necessary at some stage in order to find, store and retrieve relevant technological information. Organising the enterprise's 
technological information is a vital element in any technology intelligence process, since technology monitoring needs a system to filter and sieve the relevant information from the immaterial. The ontology concept has been utilised to achieve the above objectives.

\section{BACKGROUND - UNDERLYING CONCEPTS}

\subsection{Knowledge management}

McCune [2] describes the process of knowledge management as "the task of developing and exploiting an organization's tangible and intangible knowledge resources". Exploiting both types of knowledge is a challenging issue for enterprise success. Capturing and displaying various forms of knowledge (i.e. implicit and explicit, including the relationships between various clusters of knowledge, is defined as knowledge mapping [3]. In order to achieve the above tasks several software applications have been developed such as groupware programs, data warehouses, intranet and document management [2] .

Knowledge management can provide a formalised structure to help in capturing the right/critical information externally and internally to the enterprise.

\section{2 Technology intelligence}

The activity of collecting and evaluating information on technology developments has been given several names including technology intelligence, technology monitoring, technology forecasting, technology scouting, competitive technical intelligence, and technology intelligence [4]; we shall use the term technology intelligence (TI).

Most strategic managers claim that their companies keep up-to-date in their field; however few such managers have a systematic way to capture the important elements of technology changes from the general information around them [5]. Technology Intelligence can be used to capture external and internal information and identify promising technologies, to show their potential as well as their limits. It can highlight emerging technologies or new technology combinations, products or services that have the potential to replace the current dominant technology in the market. By highlighting potential replacement technologies, technology intelligence can enable enterprises to take early action to avoid disruptions that would compromise the balance sheet.

\section{3 Ontologies and their role in technology intelligence}

The word ontology was taken from philosophy, where it means a systematic explanation of being. Corcho et al [6] state that the word 'ontology' is now becoming a more relevant word for the knowledge engineering community.

Ontologies enable common understandings of the structure of information among people or software agents, and the answering of queries from technologists. This paper describes the application of ontologies to detect relationships between apparently unconnected concepts such as products, materials, technologies; where several events or changes occur that are seen to be linked via ontological connections, alarms can be raised to initiate an action to respond to these changes, which represent a threat or opportunity associated with the company core competences. 
The role of an ontology-based system is shown in Figure 1. Technological information is collected using technology intelligence tools. Then it is stored, updated and sieved via the system to identify critical technological issues relevant to the company. The ontology-based system is explained further in Section 3.1, and an explanation of how the system acts as a filter for technological information is provided.

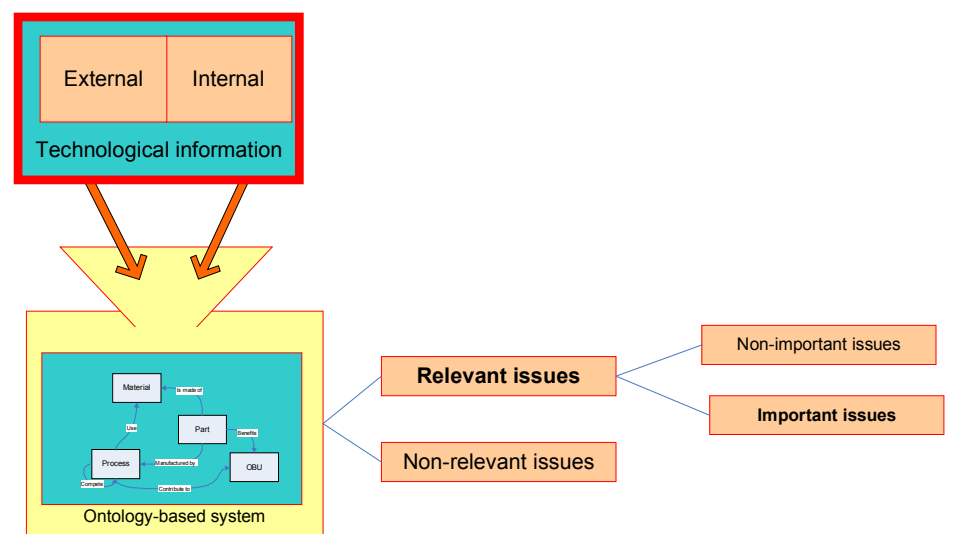

Figure 1. The role of ontology-based system in technology intelligence function

Kayed [7] suggests that the life cycle of ontology design can be split into three major stages; building, manipulating and maintaining. In the building stage, purpose, scope and ontology requirements are identified. Then data is collected about the application.

\section{AN ONTOLOGY-BASED KNOWLEDGE MANAGEMENT SYSTEM}

The authors have developed and implemented a prototype ontology-based knowledge management system, and tested it in a high technology manufacturing enterprise.

\subsection{Ontology-based system}

Data and information collection processes has been performed to accumulate concepts related to the case enterprise areas of interest. The sources of information used were from published literature and experts in manufacturing engineering. Published literature includes patents, newspapers, magazines, trade journals, academic journals. The experts in manufacturing engineering were interviewed in the company.

The ontology can be divided into an information ontology and a domain ontology [8]. The information ontology describes knowledge objects and contains generic concepts and attributes of all information about knowledge objects, such as the material name, material specifications, material applications. The domain ontology consists of the concepts, attributes, and instances of the application (in this case study, manufacturing technologies). The purpose of domain ontology is to achieve the objective of semantic match when searching for knowledge objects. Figure 2 highlights the structure of the ontology-based knowledge system and describes the 
required relationships that exist between the concepts providing the formation of "material" as a knowledge object.

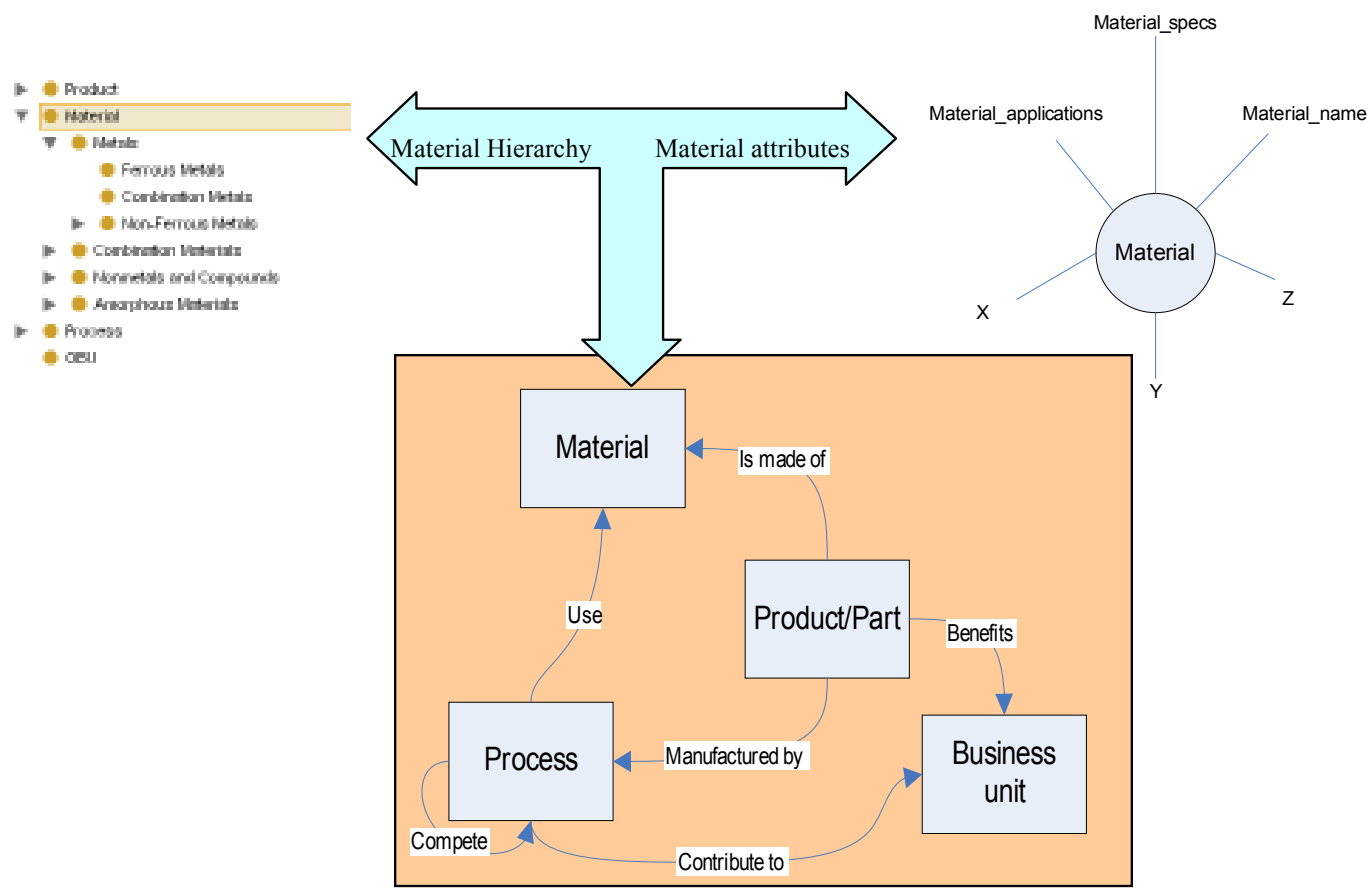

Figure 2. The ontology-based system

\subsection{Implementation in an advanced manufacturing enterprise}

The system has been developed as part of a technology intelligence oriented concept to help in maintaining technological database which contains product technology, material technology and process technology. Furthermore, all the hierarchies and attributes are identified. The hierarchies explain the concept relations graphically (i.e. the subclass relation) which means that the concept is part of the super concept (see the "material" hierarchy in Figure 2).

In advanced manufacturing enterprises, it is essential to build the above ontologies before applying the text mining and Internet search tools. Therefore, we need company-specific "agreed on" concepts that comprise these ontologies.

The prototype system has been developed using real data from an advanced manufacturing company based in the UK. This data has included most of the technologies (product, material, manufacturing processes). The system has been tested partially using the above data. Queries and questions were raised to examine the knowledge-base. Parts of the domain ontology are depicted in Figure 3, which is a screen shot of Protégé-2000 using the TGVizTap plug-in.

The basic components of the ontology include a comprehensive hierarchy for each item identified in the ontology system shown in Figure 2. For example, in materials and manufacturing processes, a well-organised taxonomy has been produced based on the taxonomies available by the Integrated Manufacturing Technology Initiative [9]. 


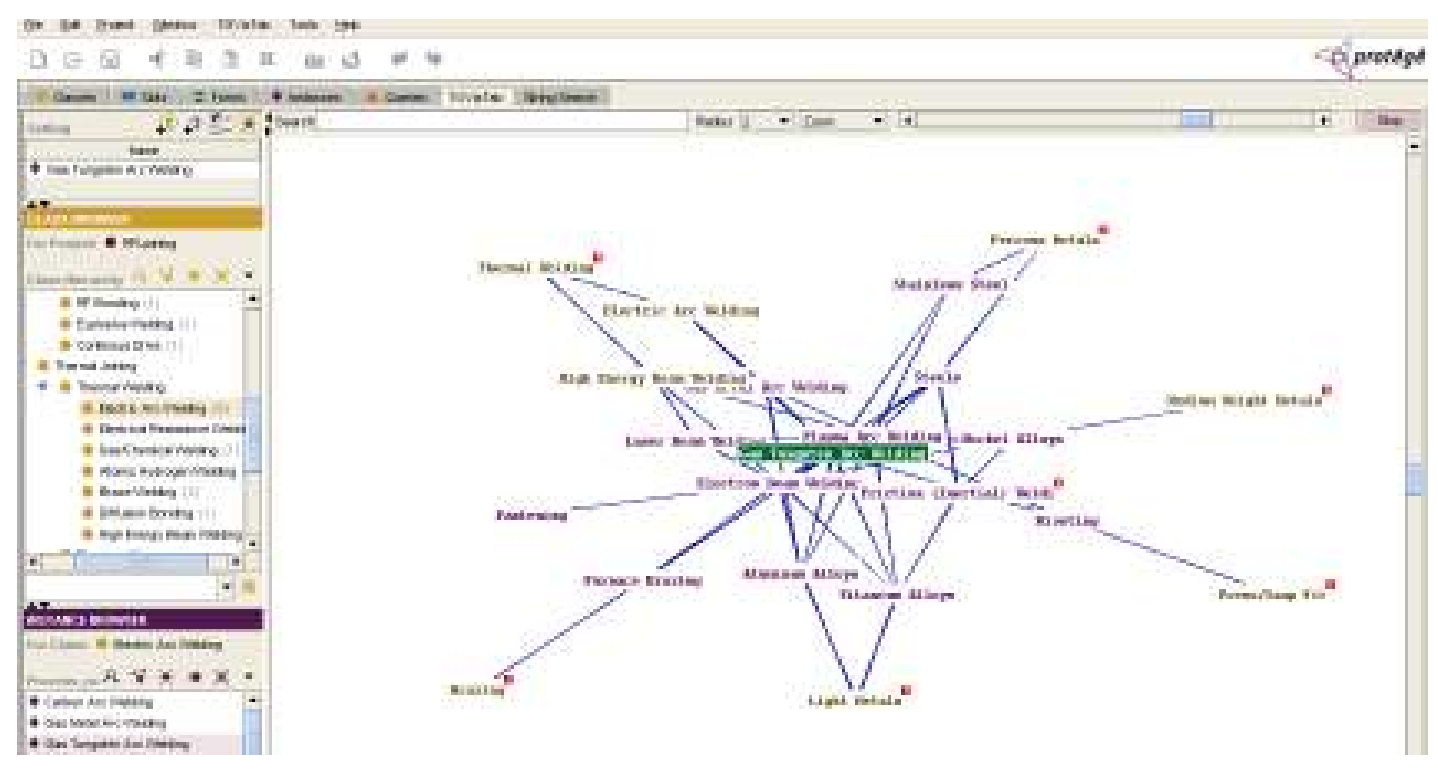

Figure 3. Parts of domain ontology in Protégé using TGVizTap plug-in

Using the attributes, which are called slots in Protégé, all the necessary relationships are built to help in formalising all the required knowledge for any analysis exercises such as technology forecasting which is part of technology watch (TW) methodology [10]. Having this system will enable a technologist, for example, to utilise a new development in a material technology which was updated by a material expert who is well aware of its consequences on various applications.

\section{CONCLUSIONS}

The accelerating rate of technology change is increasing the risks that technologyorientated companies face. For that reason, an integrated knowledge management system to support technology intelligence is required to alleviate these risks by providing early warnings of potential changes.

The system outlined in this paper is intended to help in searching proactively for information on potential technology-related developments. Analysis and assessment exercises supply relevant personnel with the required information. Filtering the technological information as part of technology intelligence is not effective without such a system; hence integrating this system within technology intelligence is vital to provide intelligent information for the decision-makers.

This ontology-based system has been developed at the University of Nottingham as part of a technology watch methodology which aims to help organisations in monitoring technological developments associated with product, processes and material of concern to them. It has been implemented in advance manufacturing company and further computer integration system is required.

\section{ACKNOWLEDGMENT}

The authors gratefully acknowledge support from the UK EPSRC. 


\section{References}

1. Phaal R, Rick Mitchell, \& David Probert 2003, "Technology roadmapping: Starting-up roadmapping fast", Research Technology Management, Washington, vol. 46, no. 2.

2. McCune, J. 1999, "Thirst for knowledge", Management Review, vol. 8, no. 4, pp. 10-12.

3. Vail E.F. 1999, "Knowledge mapping: getting started with knowledge management", Information Systems Management, vol. Fall 1999, pp. 16-23.

4. Bucher, P. 2003, Integrated Technology Roadmapping: Design and Implementation for Technology-Based Multinational Enterprises, PhD, Swiss Federal Institute of Technology Zurich.

5. Ashton, W. B. \& Stacey, G. S. 1995, "Technical Intelligence in Business: Understanding Technology Threats and Opportunities", International Journal of TechnologyManagement, vol. 10, no. 1.

6. Corcho, O., Fernandez-Lopez, M., \& Gomez-Perez, A. 2003, "Methodologies, tools and languages for building ontologies. Where is their meeting point?", Data \& Knowledge Engineering, vol. 46, no. 1, pp. 41-64.

7. Kayed, A. \& Colomb, R. M. 2001, "Extracting Ontological Concepts for Tendering Conceptual Structures", Data and Knowledge Engineering Journal, vol. 41, no. 1.

8. Abecker, A., Bernardi, A., Hinkelmann, K., Kühn, O., \& Sintek, M. 1998, "Toward a Technology for Organizational Memories", IEEE Intelligent System, vol. 13, no. May/June, pp. 40-48.

9. IMTI. http://www.imti21.org/ . 8-2-2007.

Ref Type: Electronic Citation

10. Arman, H., Hodgson, A., \& Gindy, N. N. Z. 2006, "Threat and opportunity analysis in technological development", in Portland International Conference on Management of Engineering and Technology (PICMET), Istanbul, pp. 9-17. 